\title{
DEL VOLUNTARISMO JURÍDICO A LA RAZÓN PRÁCTICA EN EL DERECHO
}

From legal voluntarism to practical reason in Law

Dal volontariato legale alla ragione pratica nella Legge

Rodolfo Vigo ${ }^{1}$

\begin{abstract}
Para citar este artículo:
Vigo, R. (2020). "Del voluntarismo jurídico a la razón práctica en el Derecho". Prudentia Iuris, N. Aniversario, pp. 79-95. DOI: https://doi.org/10.46553/prudentia.aniversario.2020.pp.79-95
\end{abstract}

Resumen: Durante la vigencia plena del Estado de Derecho Legal (desde la Revolución Francesa hasta después de la Segunda Guerra) predominó, entre los juristas, primero, la teoría iuspositivista legalista y, luego, la teoría pura kelseniana. En ese marco la creación del Derecho era fruto de la voluntad del legislador o del particular por medio del contrato, no requería ninguna justificación racional para sostener la validez de la norma jurídica. En tiempos del Estado de Derecho Constitucional (EDC) se confirma la tesis de la necesaria reconciliación del Derecho con la razón práctica valorativa o moral, apelando a la filosofía aristotélico-tomista o a la kantiana. La validez de toda norma jurídica exige el control de justificación racional, de modo que el control de constitucionalidad se asimila al control de racionalidad. La doctrina de la sentencia arbitraria confirma esa teoría de la validez, y ella está respaldada no solo por la Constitución argentina sino también por razones intrínsecas u ontológicas del Derecho. Es posibile identificar hasta once exigencias de esa racionalidad que determina la existencia o validez de una norma jurídica.

1 Profesor emérito de la Facultad de Derecho de la Pontificia Universidad Católica de Argentina, Buenos Aires, Argentina. Miembro de la Academia Nacional de Derecho y Ciencias Sociales. Correo electrónico: rodolfovigo@uca.edu.ar. 
Palabras clave: Validez jurídica; Justificación racional; Voluntarismo; Control de constitucionalidad.

Abstract: During the plenary validity of the State of Legal Law (from the French Revolution until after the Second War), jurists predominated, first the legalistic iuspositivist theory and then the pure Kelsenian theory. In this framework, the creation of the law was the result of the will of the legislator or the individual through the contract, it did not require any rational justification to maintain the validity of the legal norm. In times of the State of Constitutional Law (EDC), the thesis of the necessary reconciliation of law with practical evaluative or moral reason is confirmed, appealing to Aristotelian-Thomist or Kantian philosophy. The validity of any legal norm requires the control of rational justification, so that control of constitutionality is assimilated to control of rationality. The doctrine of arbitrary sentence confirms this theory of validity, and it is supported not only by the Argentine Constitution but also for intrinsic or ontological reasons of law. It is possible to identify up to eleven requirements of that rationality that determines the existence or validity of a legal norm.

Keywords: Legal validity; Rational justification; Voluntarism; Control of constitutionality.

Sommario: Durante la piena validità dello Stato di Diritto (dalla Rivoluzione Francese fino al dopoguerra) predominarono i giuristi, prima la teoria iuspositiva legalistica e poi la pura teoria kelseniana. In questo quadro, la creazione del diritto era il risultato della volontà del legislatore o dell'individuo mediante contratto, non richiedeva alcuna giustificazione razionale per sostenere la validità della norma giuridica. In tempi di Stato di Diritto Costituzionale (CED) si conferma la tesi della necessaria riconciliazione del diritto con la valutazione o ragione morale pratica, facendo appello alla filosofia aristotelico-tomista o kantiana. La validità di tutte le norme legali richiede il controllo della giustificazione razionale, in modo che il controllo della costituzionalità sia assimilato al controllo della razionalità. La dottrina del giudizio arbitrario conferma questa teoria della validità, ed è supportata non solo dalla Costituzione argentina ma anche da ragioni di diritto intrinseche o ontologiche. È possibile identificare fino a undici requisiti di quella razionalità che determina l'esistenza o la validità di una norma giuridica.

Parole chiave: Validità legale; Giustificazione razionale; Volontariato; Controllo di costituzionalità. 


\section{Propósito}

En la presente nota nos proponemos analizar sucinta y centralmente las conexiones entre la razón y la voluntad con el Derecho. Sabemos que aquellas son facultades humanas, pero que han sido definidas de manera muy distinta por parte de diferentes e importantes autores, y, a su vez, esas precisiones terminan de proyectarse al campo jurídico también de diversas maneras. Al margen de esas discusiones, partiremos de asociar elementalmente la razón con la capacidad de conocer ("teóricamente": diciendo cómo son las cosas y estructurando razonamientos; o "prácticamente": discerniendo y dirigiendo la conducta humana) y la voluntad con la capacidad de querer y concretar las operaciones humanas. En términos rigurosamente kantianos, la razón teórica tiene por objeto discernir qué es lo que podemos conocer, mientras que la razón práctica nos indicará cómo debemos actuar.

Nuestro interés central es la razón práctica, que podríamos también llamar axiológica, moral o ética, en tanto juzga desde el bien o los valores a las conductas y, por extensión, su resultado, como normas, instituciones, hábitos, etc. Esa precisión es importante, dado que hay otras modalidades de la racionalidad guiando a la praxis humana, pero no ya en orden al bien sino en orden a la belleza (razón práctica estética o artística), o en orden a obtener un cierto resultado transformando cosas no humanas (razón práctica pragmática, técnica o utilitaria).

\section{De Tomás de Aquino a Francisco Suárez}

La teoría jurídica propuesta por el Aquinate claramente proclama la íntima conexión entre el Derecho y la razón; ello se verifica al definir la ley como "ordenación de la razón" ("ordinatio rationis"2) y al designar el saber prudencial jurídico como la matriz del Derecho concreto. Tal descripción no implica negar la voluntad, dado que siendo su objeto el querer, dicha facultad apetitiva se hace presente para instar al conocimiento, como para luego operar o llevar a cabo el acto elegido por el saber práctico prudencial circunstanciado. Veámoslo en un ejemplo elemental: el juez necesita saber cuál es la sentencia justa que debe dictar en ese proceso, y esa pregunta la remite al saber prudencial; sin embargo, la voluntad importa en tanto está presupuesto el querer del juez por ser justo, pero además, una vez que la razón escoge la resolución a dictar, es necesario que el juez proceda a

2 Tomás de Aquino. Suma Teológica, I-II, 90, 4. 
instancia de su voluntad a redactar y firmar la sentencia y que ella finalmente sea operativa o eficaz. Desde esa teoría inspirada en Aristóteles y continuada por Tomás de Aquino, la verdad práctica no está en algo exterior al sujeto, dado que ella refiere a la orientación de la conducta que va a realizarse, y por eso consiste en cierta adecuación entre la razón que juzga sobre los medios y la voluntad que quiere el fin o el bien que plenifica al ser humano y cuya posesión genera la felicidad correspondiente y proporcional. La practicidad del saber es algo variable en intensidad, y así ella aparece debilitada o en su mínima expresión en el plano de los primeros principios que coinciden con los fines más universales del obrar humano, en cuanto orientado a procurar el bien y la consiguiente felicidad; y también alcanzará su máxima practicidad en el plano de las conductas concretas y contingentes, donde, consiguientemente, se encontrará más disminuida tanto la necesidad como su certeza. La prudencia opera como una especie de puente-saber entre aquellas verdades más generales y universales (por ejemplo, las proporcionadas por la ciencia moral) y las conductas contingentes e históricas que procura dirigir, pero como el conocimiento de los singulares se obtiene por los sentidos y la experiencia, resulta que la prudencia se adquiere con su ejercicio y con la memoria respectiva. De ahí que Aristóteles advertía que los jóvenes pueden ser buenos matemáticos, aunque será difícil que sean plenamente prudentes dado que les falta experiencia, pues la prudencia es de aquellas cosas que se saben haciéndolas. La prudencia jurídica, o sea, aquella focalizada al terreno jurídico, tiene por objeto discernir y dirigir las conductas jurídicas en tanto obligatorias, prohibidas o permitidas según el Derecho vigente y válido, por eso, ella se requiere en todo aquel que define derechos y deberes propios o ajenos; sea con alcance más general (por ejemplo, el legislador) o más concreto (por ejemplo, el juez); sea de manera heterónoma (por ejemplo, la ley) o autónoma (por ejemplo, un contrato).

Francisco Suárez, más allá de que retoma enseñanzas de la primera escolástica, es cierto que en muchas cuestiones toma distancia de la perspectiva estrictamente tomista, y algunas de ellas son muy relevantes. En efecto, y ciñéndonos al campo jurídico, con el Doctor Eximius, el Derecho, en su analogado principal, queda identificado con el Derecho Subjetivo, y la ley se asimila a la "voluntad de la autoridad" ("praeceptum commune, justum, stabile, habet promulgata"3), en tanto lo esencial pasa a ser la fuerza coactiva derivada del imperio de la voluntad. De ese modo, y sin perjuicio de las modalizaciones planteadas, lo constitutivo de la ley se identifica con el querer del gobernante y lo que él decide y promulga. Ese voluntarismo

3 Suárez, F. De legibus, 1-12. 
morigerado suareciano será alimentado y potenciado por otros autores, tales son los casos de Hobbes y Rousseau, y ya en éstos cualquier resabio de corrección racional queda descartada, a punto de que puede decirse que la voluntad absorbe a la razón y la pone a su servicio.

En respaldo de esa desconfianza o rechazo de la razón práctica, vendrá la Reforma Protestante (Lutero, Calvino, Zwinglio) a ratificar el voluntarismo teológico insistiendo que lo bueno lo es porque así lo quiere Dios, junto a la advertencia de los riesgos que conlleva para la condena divina el confiar en la razón. Se deja de lado en ese terreno la enseñanza tomista de que la fe confirma a la razón y la eleva, conforme a la cual no hay dos verdades sino una, pero a ella se puede acceder por la fe o por la razón. La matriz de la "prudencia", en donde -según la filosofía aristotélica-tomista- se generaba el "saber vivir-bien", resulta transformada radicalmente con Kant, en tanto la prudencia es redefinida en términos vinculados a optar por lo conveniente al interés personal y, de ese modo, pierde la relevancia que tenía en el saber práctico concreto -moral, jurídico o político. Aranguren, en síntesis apropiada, escribe: "Se dibujan tres concepciones fundamentales de la ética: ética de la prudencia (Sócrates), ética de la buena voluntad (Kant) y ética de la prudencia y la buena voluntad (Aristóteles)"4.

\section{El imperio de la voluntad en el Estado de Derecho Legal}

Con la Revolución Francesa y el proceso de codificación que Napoleón inicia en 1804, el voluntarismo logra ser consagrado y plasmado en la misma "ley", o sea, en el "Derecho", en tanto éste no es más que lo contenido en aquella. La ley es declarada -conforme a las enseñanzas rousseaunianas del "Contrato Social"- como "infalible" e "incontrolable", y el fundamento es que la "voluntad general" se canaliza a través del Poder Legislativo. Esa "voluntad general" será soberana y el alma del cuerpo político, mientras que la voluntad individual es el alma del cuerpo humano ${ }^{5}$."Dura lex, sed lex" es la consigna para todos los juristas, de ahí que el profesor Mourlon enseñe a los jueces: "Un buen magistrado humilla su razón ante la de la ley. Nada está sobre ella, y es prevaricación el eludir sus disposiciones so pretexto que no se encuentran de acuerdo con la equidad natural. En jurisprudencia no hay ni puede haber mejor razón ni mejor equidad que la razón y equidad

4 Aranguren, J. L. (1958). "Ética”. Revista de Occidente, 327.

5 André-Vincent (1963). "La notion moderne de droit naturel et le volontarisme". En Archives de Philosophie du droit. Buenos Aires. Ghersi. 
de la ley"6, y Aubry prescriba para el mundo académico: "Los profesores encargados de impartir a nombre del Estado la enseñanza jurídica tienen por misión protestar, mesurada, pero firmemente, contra toda innovación que tienda a sustituir la voluntad del legislador por una extraña"7. En el Derecho Privado el contrato es válido y "ley para las partes" en la medida que se ajuste a lo querido por las mismas, y esa voluntad (soberana) expresada con la firma se torna también irrevisable.

El iuspositivismo, primero legalista (escuela exegética francesa) y luego el kelseniano, es plenamente funcional a ese Estado de Derecho Legal. Ambas perspectivas coinciden en identificar al Derecho con las normas positivas o puestas por la voluntad de la autoridad, de manera que cualquier contenido puede ser Derecho en la medida que esté mandado por el órgano competente. También esas teorías postulan que los valores o la moral nada tienen que ver con el Derecho, y la teoría pura del Derecho se encarga de explicitar un inequívoco escepticismo ético que se expresa al afirmar que la justicia es "un ideal irracional" limita a describir el Derecho creado "por un acto de voluntad de autoridad humana"9. Coherentemente, llega a declarar Kelsen que "el acto de interpretación jurídica no es de conocimiento sino de voluntad"10; es que no hay ninguna posibilidad de acudir a la razón con la pretensión de que ella defina la mejor o más valiosa conducta u opción. Muerta o condenada la razón práctica, valorativa o moral, e identificados los juicios que se pronuncian en ese terreno con las emociones subjetivas o irracionales, la única razón que queda (enseñó el positivismo lógico del Círculo de Viena ${ }^{11}$, a fines de la década del veinte) es la teórica o especulativa, que se limita a describir las cosas por medio de proposiciones demostrativas, verificables o a posteriori (propias de la física), o la alternativa de confiar el conocimiento por medio de proposiciones verdaderas por su forma, o sea, tautológicas o apriorísticas (propios de la lógica o las matemáticas). La filosofía conforme a esa matriz del empirismo lógico queda reducida a análisis lógico de los enunciados científicos.

6 Bonnecase, J. (1994). La escuela de la exégesis en Derecho Civil. México. Cajica, 160.

7 Ibídem 141.

8 Kelsen, H. (1979). Teoría general del Derecho y del Estado. México. UNAM, 15.

9 Ibídem, 10.

10 Kelsen, H. (2000). Teoría pura del Derecho. México. Ed. Porrúa, 353.

11 Cfr. Carnap, R. (1965). "La superación de la metafísica por medio del análisis lógico del lenguaje”. En El positivismo lógico. México. FCE, 66 y (1985). Manifeste du Cercle de Vienne. Ed. Antonia Soulez. P.U.F. 


\section{La rehabilitación de la razón práctica}

Luego de la experiencia histórica del "mal radical" del nazismo, son muchos los que se preguntarán cómo es posible que la razón permanezca sin ninguna respuesta frente a la evidencia de algo que se capta inmediatamente como contrario al hombre y a su razón. Frente a los que postulan el "derecho" de matar o eliminar a los que pertenecen a una "raza inferior", la razón ¿está condenada a permanecer en silencio? A partir de esa dramática y básica pregunta, son varios los que vuelven especialmente a Aristóteles y a Kant ${ }^{12}$ para tratar de reivindicar un espacio a la razón práctica, como para que ella se pronuncie y juzgue como buenas (o malas) o correctas (o incorrectas) ciertas conductas, normas o instituciones.

Los interrogantes e inquietudes mencionados son potenciados cuando ya en tiempos del Estado de Derecho Constitucional, la "moral racional" se incorpora ("emigra", según expresión difundida por Habermas) al Derecho dentro de los rótulos de Derechos Humanos, principios, valores o bienes, e, incluso, esa materia se reconoce como los criterios axiológicos desde los cuales debe juzgarse el Derecho en orden a determinar su validez o invalidez. "La injusticia extrema no es derecho", proclama el Tribunal de Núremberg, apelando a la fórmula de Radbruch, y al hacerlo se reconoce que hay algún limite sustancial que pone la moral o la razón para la existencia del Derecho, y que ese límite puede ser reconocido por cualquier razón humana, de modo que su violación o ignorancia ya no puede ser justificada. Los Tratados de Derechos Humanos reflejan en su redacción aquella confianza cognoscitiva y objetiva de la razón práctica, al declarar que ellos no se "crean" sino que se "reconocen", que resultan inalienables a cualquier voluntad (incluida la soberana de los Estados) y que tienen vigencia universal.

La filosofía jurídica hoy, al menos en autores apoyados en Kant, como Alexy, Atienza, Nino, etc., o avalados por Aristóteles y Aquino, como Finnis, Viola, Ollero, etc., reconocen que la razón puede respondernos algunas preguntas de índole moral o axiológica, y esas respuestas se traducen en exigencias de índole sustancial, pero también en el plano formal o procedimental.

Si vamos a Robert Alexy, repasemos algunas tesis de su teoría no positivista, discursiva y dialógica, las que confirman la reconciliación entre el Derecho y la razón: a) "el diálogo racional necesita del Derecho para alcanzar realidad, y el Derecho necesita del diálogo racional para alcanzar

12 Cfr. Riedel, M. (ed.) (1972-1974). Rehabilitierung der pracktischen Philosophie. Freiburg i. B. Rombach, 2 vols. 
legitimidad"13; b) "los problemas de justicia son problemas morales", y "es posible argumentar racionalmente en materia de justicia, lo que posibilita superar la emotiva-subjetiva"14; c) "el discurso jurídico es un caso especial del discurso práctico general"15; d) "la teoría del discurso conduce al Estado democrático constitucional porque formula dos exigencias fundamentales en relación al contenido y la estructura del sistema jurídico: los Derechos Humanos y la democracia"16; e) participar en la forma de vida humana más elemental y universal supone recurrir a "aserciones", o sea, "actos de habla con los cuales se plantea una pretensión a la verdad o a la corrección"17; f) la doble naturaleza del Derecho implica, por un lado, su aspecto real o institucional, o sea, lo legal y lo eficaz, y, por el otro, su "dimensión ideal o discursiva”; y g) sin metafísica no pueden sostenerse los Derechos Humanos, y éstos se definen como universales, fundamentales, abstractos, morales y prioritarios, y no pueden "ser derogados por normas de Derecho Positivo [...] son la medida a la que debe ajustarse toda interpretación de lo positivizado"18. En la teoría alexyana rechazar la conexión entre el Derecho y la moral o la razón, implicaría la necesidad de aceptar "contradicciones performativas"19, tales como reconocerles juridicidad a una Constitución que en su artículo primero se propone que las normas jurídicas a dictarse serán ininteligibles e injustas, o a una sentencia judicial escrita en un lenguaje que solo conoce su autor. Esas normas no solo resultan disparatadas o absurdas, sino que incurren en una falla conceptual en tanto el Derecho formula implícita y necesariamente una pretensión de corrección o de justificación racional.

Igualmente en John Finnis encontramos esa conexión intrínseca entre Derecho y razón práctica: a) la filosofía práctica (inescindiblemente incluye al Derecho, la moral y la política) es "una reflexión disciplinada y crítica sobre los bienes que pueden realizarse en la acción humana y sobre las exigencias de la razonabilidad práctica" 20 ; b) "el criterio de conformidad o contrariedad respecto a la naturaleza humana es la razonabilidad [...] El bien del ser humano consiste en estar conforme con la razón, y el mal huma-

13 Alexy, R. (2000). "La institucionalización de la razón”. En Persona y Derecho. Pamplona. Universidad de Navarra, vol. 43, 237.

14 Alexy, R. (2002). "Recht und Moral". En Harle, Wilfried-Preul, Reiner (eds.). Ethik und Recht. N. G. Elwert Verlag. Marburg, 85.

15 Alexy, R. (1993). Derecho y razón práctica. México. Fontamara, 55.

16 Alexy, R. "La institucionalización de la razón". Cit., 238.

17 Alexy, R. (1995). Teoría del discurso y derechos humanos. Universidad Externado de Colombia, 79.

18 Alexy, R. (2008). “¿Derechos Humanos sin Metafísica?”. En Anuario de la Asociación Argentina de Filosofía del Derecho "Ideas y Derecho". Buenos Aires.

19 Alexy, R. (1997). El concepto y la validez del Derecho. Barcelona. Gedisa, 44.

20 Finnis, J. (2000). Ley natural y Derecho Natural. Buenos Aires. Abeledo Perrot, 48. 
no insiste en estar fuera del orden de la razonabilidad [...] para Tomás de Aquino, la manera de descubrir qué es moralmente recto (virtud) y desviado (vicio) no es preguntar si está de acuerdo a la naturaleza humana, sino qué es razonable"21; c) los primeros principios de la razonabilidad práctica, o "primeros principios de la ley natural, que especifican las formas básicas del bien y del mal y que pueden ser captados adecuadamente por cualquiera que tenga uso de razón (y no sólo por metafísicos), son per se nota (evidentes) e indemostrables [...] No son inferidos o derivados de nada. Son inderivados (aunque no innatos)", esos principios communissima se comprenden "experimentando la propia naturaleza, por decirlo así, desde adentro, bajo la forma de las propias inclinaciones"22; d) entre esos principios primeros 0 "bienes humanos básicos" está la "razonabilidad práctica": el orden inteligente en acciones, hábitos y actitudes prácticas, tanto en su aspecto interno -de las acciones y disposiciones- como en su aspecto externo -correspondencia auténtica entre preferencias, valoraciones y autodeterminaciones-; e) junto a esa racionalidad práctica manifestada sustancialmente en los bienes humanos básicos, Finnis afirma el método o el procedimiento como para definir aquel plan de vida que nos permitirá "vivir-bien": plan de vida coherente; ninguna preferencia arbitraria entre los valores, ni entre las personas; desprendimiento y desapego; eficiencia razonable; respeto a todo bien humano básico en todo acto y a las exigencias del bien común; y seguir la propia conciencia; y f) los Derechos Humanos constituyen "una forma de expresar virtualmente todas las exigencias de la razonabilidad práctica" ${ }^{23}$, ellos "clasifican y expresan las exigencias de la justicia [...] una expresión enfática de lo que está implícito en el bien común"24.

\section{La recepción de la razón en la jurisprudencia}

La jurisprudencia norteamericana tempranamente asimiló, en buena medida, el control de constitucionalidad al control de racionalidad, apelando para ello a las Enmiendas V (1791) y XIV (1868), entendiendo el due process of law, no solo en términos procesales, sino también sustanciales. En Latinoamérica, la jurisprudencia ha ido incorporando progresivamente en el control de constitucionalidad el control sobre el derecho en cuestión, sometiéndolo a comprobar su racionalidad o razonabilidad; $\mathrm{y}$, al respecto, en la Argentina la Corte Suprema ha ratificado la tesis de que la sentencia debe

21 Ibídem, 69.

22 Ibídem, 68.

23 Ibídem, 239.

24 Ibídem, 243. 
ser "derivación razonada del Derecho vigente a la luz de las constancias de la causa y no producto de la individual voluntad del juez" (Fallos: 291-382; 292-254; 293-176; 302-967; 303-120; 306-717; 320-702, 321-1909, 323-1019, 327-931; 333-1273; etc.).

Como ha coincidido sin mayores dificultades la doctrina nacional, el fundamento constitucional de la racionalidad en el Derecho está en los artículos $1^{\circ}$ (sistema republicano), 17 (derecho de propiedad), 18 (debido proceso), 19 (principio de legalidad), 28 (principio de razonabilidad), 31 (supremacía constitucional), 33 (derecho innominado a contar con un derecho justificado racional) y en el mandato preambular de "afianzar la justicia"; pero puede aducirse que ese reclamo de armonizar Derecho con la razón remite a la necesidad de que el Derecho responda a sus exigencias intrínsecas asumiendo un rostro plenamente humano, en tanto pretende que la autoridad brinde razones que justifiquen su ejercicio autoritativo, y por esa vía permita su comprensión, su control y hasta su cumplimiento voluntario, o dicho sintética y omnicomprensivamente, que la totalidad de las normas que integran el Derecho argentino no sólo sean vigentes, sino también válidas. Un Derecho sin razones justificatorias equivale a suponer destinatarios igualados a animales, en tanto incapacitados para conocer el valor de ese Derecho, y al consiguiente riesgo de un Derecho contra el hombre, su sociedad y sus derechos. En esa mirada hacia el Derecho Positivo argentino, corresponde destacar que el nuevo Código Civil y Comercial recepciona explícita y reiteradamente esa necesidad de un Derecho que sea "razonable"; ello se comprueba en los artículos $3^{\circ}, 553,1011,1019,1041$ inc. b, 1184, 1685, 1710, etc. En definitiva, lo que se pretende -reiteramos- es que el Derecho (cualquiera sea el que lo formule: constituyente, legislador, administrador, juez, sociedad, particular, etc.) vigente sea válido o conforme a la razón, y así pueda ser comprendido integralmente por el destinatario cuando lo somete a verificar su racionalidad.

Vale aquí cuestionar la distinción enarbolada por el iuspositivismo legalista entre "creación" y "aplicación" del Derecho, dado que quien pone Derecho en algún sentido aplica y al mismo tiempo algo crea, al margen de las magnitudes de esas tareas que se pueden constatar en cada sociedad según el régimen político-jurídico establecido. También es oportuno advertir que la presencia de la razón y la voluntad resultan ineludibles en el acto de formulación del Derecho, aunque esa presencia puede ser más o menos importante a tenor de las características de la norma dictada y del referido sistema jurídico-político. Por otro lado, la tentación de reclamar racionalidad solo al juez y tolerar la voluntad del legislador sin control racional, supone postular una imposibilidad casi esquizofrénica, dado que la irracionalidad de la ley contaminará ineludiblemente de irracionalidad a lo que sigue. 


\section{Simplemente "racionalidad"}

Es cierto que la teoría jurídica ha debatido mucho en las últimas décadas sobre cómo definir a la "racionalidad" y a la "razonabilidad", y cuáles serían sus coincidencias y sus diferencias. A esa discusión se ha sumado otro concepto en disputa, que es el de "proporcionalidad", con el que pueden comprobarse solapamientos entre ellos. Al margen de que hay un uso amplio que asimila la racionalidad al respeto de las exigencias de la lógica, mientras que la razonabilidad se conecta con lo valioso en términos axiológicos, nos parece que la noción más abarcativa puede estar simplemente en la racionalidad, o sea, en aquello conforme o ajustado a la razón humana integralmente considerada (tanto teórica, respetando las exigencias lógicas, como la razón práctica: ajustándose a las exigencias nucleares axiológicas, morales o éticas). Las fórmulas utilizadas en la jurisprudencia argentina resultan compatibles con lo postulado, en tanto admiten que el control de constitucionalidad se ejerce sobre lo "irrazonable, inicuo o arbitrario" ( $F a$ llos: 340-1480), o se lo reconoce como un control "de la legalidad, razonabilidad y proporcionalidad" (Fallos: 339-1077).

Al reclamar "racionalidad" en el Derecho, no se está pretendiendo una razón sofisticada o solo instruida científicamente, sino aquella más elemental y extendida, que en terminología anglosajona se reconoce como "common sense" atribuible a un "reasonable man", aunque con las restricciones y exigencias que pondrá institucionalmente el Derecho vigente y válido en esa sociedad. En el artículo 54 del Código Modelo de Ética Judicial para Iberoamérica (aprobado por las veintidós Cortes Suprema de dicho espacio geográfico) se refleja la tesis aludida, cuando se le reclama al "juez íntegro" que se comporte de la manera que exige "un observador razonable". Recordemos e insistamos que en la filosofía clásica esa capacidad para conducir la vida de conformidad al bien humano o al "florecimiento humano" era fruto de la prudencia, y ésta no se adquiría mediante el estudio, sino mediante la experiencia y la memoria, apoyándose en una razón capacitada para identificar la conducta mejor humanamente hablando ("razón recta"), y también en una voluntad recta habituada a querer también lo mejor. Pretender que alguien cumpla una norma que resulta para un observador razonable notoriamente ininteligible o injustificada, es someterlo a una violencia que la autoridad pueda dar por superada en la medida que exhiba las razones que la respaldan y justifican. Más allá de las zonas grises que suponen aquellos conceptos, ellos también permiten identificar zonas donde claramente se comprueba que el Derecho, si pretende asumir un rostro o una matriz humana, debe ser racional y justificado, y si no lo es, termina identificándose con violencia o irracionalidad. Precisamente las teorías de la argumentación se han abocado a desplegar todo un aparato conceptual destinando a exigir 
y controlar, desde la razón, lo mandado por la autoridad. Asimismo, esos reclamos por la argumentación no se han reducido al campo judicial, sino que se han extendido y modalizado respecto a todas las fuentes del Derecho. Es cierto que la tarea de los jueces es definir cuál es el Derecho vigente y válido, pero a veces, al decirlo, pueden violentar en su misma sentencia a la razón, aunque lo que se pretende es que la jurisprudencia expulse del Derecho las normas que contradicen la constitución y el Derecho.

\section{Racionalidad como validez jurídica}

Desde esa visión amplia de la racionalidad, quedan comprendidas en ella tanto la razonabilidad como la ponderación o la proporcionalidad, e incluso nos parece que aquel concepto puede llegar a identificarse con el de validez jurídica, en el sentido de que solo puede reconocerse como Derecho aquello que supera el test de justificación racional. En definitiva, merece ser descalificado o invalidado en términos jurídicos, lo que resulta evidente y gravemente irracional.

Estimo que el desarrollo de la jurisprudencia argentina en torno al recurso de inconstitucionalidad por sentencia arbitraria y los debates doctrinarios al respecto, son un buen banco de pruebas de lo que hemos estado analizando en cuanto a la necesaria conexión entre Derecho y razón. Es que cuando vamos a los repertorios jurisprudenciales, la enorme variedad de hipótesis de la arbitrariedad nos habla, en última instancia, de algo que no alcanza a justificarse con la razón o excede el marco de razonabilidad tolerable, y que, por ende, sólo descansa en la voluntad o el poder de alguien. Podemos coincidir con aquellos que descalifican una sentencia arbitraria por ser contraria a la constitución, pero nos parece que esa descalificación responde a motivos más raigales; en efecto, el problema es ontológico o conceptual, pues si hemos asociado intrínsecamente el Derecho con algo generado por la razón práctica o que no violenta de manera grave y evidente sus exigencias, en el supuesto de comprobarse que aquello que pretende ser reconocido como Derecho no logra ser justificado racionalmente, corresponde negarle esa calidad de jurídico. En síntesis, una sentencia arbitraria no solo no es constitucional, sino que no satisface las exigencias intrínsecas que requiere el objeto Derecho.

Desde esa lógica, la teoría de la arbitrariedad perfilada pretoriamente, en la Argentina, es una teoría sobre la invalidez o incompatibilidad de lo que procura en términos racionales ser admitido como parte del Derecho vigente y válido. Veíamos arriba, en las teorías de Alexy y Finnis, que al Derecho lo acompaña constitutiva o esencialmente la pretensión de racionalidad y de corrección, de modo que si los jueces -que son los encargados 
en última instancia de definir cuál va a ser el Derecho vigente y válido en la sociedad-comprueban que una norma (constitucional, legal, administrativa, judicial, consuetudinaria, contractual, etc.) invoca juridicidad, pero no supera el test de justificación racional, les compete a ellos expulsarla del Derecho, no obstante la pretensión de pertenencia que pudo acompañar a su nacimiento por parte del autor respetivo. Junto a esa exigencia ontológica de rechazar como Derecho válido lo evidentemente irracional, el Derecho Positivo argentino recepta en plena sintonía con un Estado de Derecho Constitucional, que la función judicial consiste en derivar razonadamente desde el Derecho vigente y válido la solución para el caso en su jurisdicción. Lo que se dice o reclama de la sentencia judicial corresponde extenderlo a toda manifestación autoritativa o voluntaria que pretende crear Derecho, y ello -insistamos- no sólo porque lo reclama la Constitución argentina, sino porque lo exige la naturaleza misma del Derecho.

Son varios los autores que han denunciado las dificultades que se enfrentan a la hora de proponer un concepto claro sobre la arbitrariedad en el Derecho, y ello responde -pensamos- a que las hipótesis de irracionalidad en el Derecho efectivamente pueden ser muy variadas. Recordando que según Aristóteles los opuestos pertenecen al mismo género del saber, de ese modo, al hablar de la irracionalidad, estamos hablando al mismo tiempo de la racionalidad, más allá de que siempre será más fácil identificar lo negativo que lo positivo. Por nuestra parte, hemos trabajado un concepto de validez que finalmente se asimila a lo "justificado racionalmente". Esta conexión se puede encontrar en un autor vinculado a Kant como Nino, cuando escribía: “[...] predicar validez de un sistema jurídico, o de una norma en particular, es afirmar que tiene fuerza vinculante; que sus prescripciones constituyen razones concluyentes para actuar [...] Si se desconoce la validez de un sistema jurídico o de una norma, esto equivale a negar su existencia [...] el significado de validez no es descriptivo, sino normativo: decir que un sistema o una norma jurídica particular son válidos es avalarlos, implica sostener que su aplicación y observancia son obligatorias y justificadas" ${ }^{25}$. Desde una matriz conectada a un cierto iusnaturalismo, Sergio Cotta ratifica: "Una obediencia consciente a la ley proviene del reconocimiento, no ya de su fuerza coactiva, sino de su obligatoriedad y ésta no puede imponerse, sino que se demuestra mediante un proceso riguroso de justificación. De ese modo, la ley vuelve a adquirir un carácter humano de acto de razón, pero de una razón cuyo criterio de verdad está en la naturaleza específica del hombre [...]"26. Y en estricta fidelidad a las enseñanzas de Tomás de Aqui-

25 Nino, C. S. La validez del Derecho. Buenos Aires. Astrea, 7.

26 Cotta, S. (1987). Justificación y obligatoriedad del Derecho. Madrid. Ceura, XIV. 
no, Francesco Olgiatti concluye: "[...] decir que el Derecho debe tener una justificación equivale a afirmar que la primera nota esencial de la juridicidad es la racionalidad (lo irracional -como una banda de malhechores- es antijurídico)", y "El Derecho será Derecho en cuanto expresa racionalidad y, por consiguiente, eticidad, puesto que la moral consiste en obrar secundum rectan rationem" 27.

Insistamos que la normatividad justificada instala a la misma en el Derecho gracias a su racionalidad expresada en los argumentos o razones que la fundamentan, la motivan o la respaldan. Dicha tesis conlleva intentar identificar esas exigencias racionales que debe satisfacer la norma jurídica como para concluir su validez o justificación. Quizás un modo de reconocer la relevancia de lo que estamos hablando es aludir a la alternativa contraria, o sea, que las decisiones se satisfacen con la mención expresa de la voluntad decisoria, resultando inexistente o irrelevante el aspecto justificatorio, pues en el mejor de los casos puede cubrirse ese requerimiento $a$ posteriori de la decisión como para satisfacer alguna necesidad institucional. De ese modo, las normas en cuestión sólo tendrían la parte resolutoria del caso o los casos a los que regulan, es decir, las definiciones del estatus jurídico de las conductas implicadas o los derechos que atribuyen o los deberes que imponen; pero no habría estrictamente razonamiento, es decir, no se iría desde premisas o juicios conocidos a otros que llegan a conocerse en virtud de conexiones lógicas. En síntesis, pura voluntad decisoria y ninguna justificación racional, más allá de alguna fachada justificatoria como para cubrir esas apariencias que dificultan sobradamente la legitimidad del poder respectivo.

Al margen de la hipótesis planteada de ausencia de justificación racional y del rechazo contraintuitivo que suscita, vayamos a la alternativa defendida, que puede ser reconstruida y coincidir con el test de validez o justificación racional de una norma jurídica, y al respecto reconocemos diez exigencias específicas y una más de alcance integral o trasversal ${ }^{28}$ :

a. Racionalidad orgánica (RO): la creación de Derecho (Público o Privado) remite a quien tiene competencia para ello, y resultaría contrario a ese orden exigirle que alguien debe cumplir una norma dada por quien carece del derecho de disponerla;

b. Racionalidad procedimental (RP): la razón está en condiciones de juzgar mejores y peores procedimientos para el dictado de una

27 Olgiatti, F. (1977). El concepto de juridicidad en Tomás de Aquino. Pamplona. EUNSA, 51 y 339.

28 Cfr. el cap. XII de mi libro (2015). Interpretación (argumentación) jurídica en el Estado de Derecho Constitucional. Santa Fe. Rubinzal-Culzoni. 
norma, y el Derecho discierne y precisa en ese terreno, por lo que incurre en irracionalidad o injustificación cuando surgen normas violatorias de esas definiciones institucionales;

c. Racionalidad sistémica (RS): las normas jurídicas no están aisladas, y la racionalidad requiere que ellas se ajusten entre sí respetando sus jerarquías, valores y delegaciones, de ese modo en el sistema jurídico hay características sustanciales y formales para las diferentes normas, posibilitando su validez respectiva;

d. Racionalidad lógico-lingüística (RLL): sería irracional exigirle a alguien que asumiera las consecuencias del incumplimiento de una norma jurídica cuando no tuvo la posibilidad de conocerla o comprenderla, dado que ella violenta a la lógica o se expresa en un lenguaje desconocido para él;

e. Racionalidad teleológica (RT): se violenta esta exigencia cuando la norma prescribe un medio determinado dado que busca obtener un cierto fin, pero se verifica la inidoneidad del mismo para tal propósito;

f. Racionalidad científica (RC): una norma no está justificada racionalmente cuando presupone o afirma una contradicción indiscutible con una verdad demostrada científicamente;

g. Racionalidad sociológica (RS): importa invalidación o no justificación imponer jurídicamente comportamientos que suponen violencia frente a costumbre o ethos arraigados en la sociedad que no son irracionales;

h. Racionalidad axiológica (RA): frente a lo "extremadamente" injusto o disvalioso se pierde la racionalidad y, consiguientemente, la juridicidad;

i. Racionalidad fáctica (RF): una norma jurídica racional incluye exigencias posibles de ser cumplidas por parte de los destinatarios, y estamos en un terreno irracional frente a lo imposible de cumplir;

j. Racionalidad intencional (RI): compromete la validez y justificación racional de una norma cuando su autor tiene actitudes o comportamientos que revelan o ponen sospechas graves de una intención incorrecta o no ajustada a la razón exigida o esperada;

k. Racionalidad prudencial o ponderativa (RP): su objeto es determinar en concreto la medida de la irracionalidad acreditada y si resulta lo mejor optar finalmente por la invalidez de la norma, de ese modo, es una exigencia transversal que toma en cuenta las restantes exigencias, sus magnitudes y las derivaciones de escoger una $u$ otra alternativa. 


\section{Conclusión}

Luego de esos ciento cincuenta años de vigencia del voluntarismo jurídico en el marco del Estado de Derecho Legal, en donde no se habla de la racionalidad práctica valorativa en el Derecho, corroboramos que en la segunda mitad del siglo XX, con el Estado de Derecho Constitucional ha cambiado ese paradigma y se pretende que el Derecho será reconocido como tal en tanto luzca justificado racionalmente, y concluir consiguientemente que cubierto dicho requisito es válido y obligatorio. Insistamos que esa pretensión no sólo se dirige a los jueces, sino a todo aquél que crea Derecho de acuerdo a las exigencias y marcos institucionales, por lo que pueden llegar a comprenderse hasta las normas contractuales patrimoniales.

Así, la teoría de la argumentación jurídica procura perfilar en términos racionales cómo debe hacerse toda norma jurídica, qué contenidos resultan incompatibles y cuáles necesarios como para que finalmente se admita como parte del Derecho vigente y válido a eso que se ha creado con dicho propósito. En ese ámbito de la racionalidad jurídica ya no se distingue raigalmente creación y aplicación, ni tampoco ley o resolución administrativa con sentencia judicial, pues lo relevante es que se pretende instituir obligatorios deberes jurídicos o conceder derechos.

La jurisprudencia argentina en materia de sentencia arbitraria es un interesante y revelador campo de prueba de esa tesis que rechaza o invalida lo que resulta manifiesta y gravemente irracional, y ello no sólo porque lo exige la Constitución, sino porque hay motivos raigales $u$ ontológicos que reivindican un Derecho racional.

Si bien en el presente trabajo nos hemos limitado a destacar la superación del voluntarismo jurídico y el reencuentro de la razón práctica con el Derecho, dejamos consignado que esa razón de la que hablan los kantianos no es exactamente la misma de la que habla el realismo clásico, pero en relación a esas silenciadas diferencias iusfilosóficas y sus respectivas proyecciones, nos hemos ocupado en otros escritos a los que remitimos ${ }^{29}$.

\section{Bibliografía}

Alexy, R. (2008). “¿Derechos Humanos sin Metafísica?”. En Anuario de la Asociación Argentina de Filosofía del Derecho "Ideas y Derecho". Buenos Aires.

Alexy, R. (1993). Derecho y razón práctica. México. Fontamara, 55. Alexy, R. (1997). El concepto y la validez del Derecho. Barcelona, 44.

29 En especial, nuestro libro (2015). Iusnaturalismo y neoconstitucionalismo: coincidencias y diferencias. Buenos Aires. EDUCA. 
Alexy, R. (2000). "La institucionalización de la razón”. En Persona y Derecho. Pamplona. Universidad de Navarra, vol. 43, 237.

Alexy, R. (2002). "Recht und Moral”. En Harle, Wilfried; Preul, Reiner (Eds.). Ethik und Recht. Margurg. N. G. Elwert Verlag, 85.

Alexy, R. (1995). Teoría del discurso y Derechos Humanos. Universidad Externado de Colombia, 79.

André-Vincet (1963). "La notion moderne de droit natural et le voluntarisme". En Archives de Philosophie du droit.

Aranguren, J. L. (1958). "Ética". Revista de Occidente. Madrid, 327.

Bonnecase, J. (1944). La escuela de la exégesis en Derecho Civil. México. Cajica, 160.

Carnap, R. (1965). "La superación de la metafísica por medio del análisis lógico del lenguaje”. En El positivismo lógico. México. FCE, 66.

Carnap, R. (1985). Manifeste du Cercle de Vienne. E. Antonia Soulez. PUF.

Cotta, S. (1987). Justificación y obligatoriedad del Derecho. Madrid. Ceura, XIV.

Finnis, J. (2000). Ley natural y Derecho Natural. Buenos Aires. Abeledo Perrot, 48.

Kelsen, H. (2000). Teoría pura del Derecho. México. Ed. Porrúa, 353.

Kelsen, H. (1979). Teoría general del Derecho y del Estado. México. UNAM, 15.

Nino, C. S. La validez del Derecho. Buenos Aires. Astrea, 7.

Olgiatti, F. (1977). El concepto de juridicidad en Tomás de Aquino. Pamplona. EUNSA, 51 y 339 .

Riedel, M. (ed.) (1972-1974). Rehabilitierung der pracktischen Philosophie. Freiburg i.B., Rombach, 2 vols.

Suárez Francisco. De legibus, 1-12.

Tomás de Aquino. Suma Teológica, I-II, 90, 4.

Vigo, R. (2015). Interpretación (argumentación) jurídica en el Estado de Derecho Constitucional. Santa Fe. Rubinzal-Culzoni.

Vigo, R. (2015). Iusnaturalismo y neoconstitucionalismo: coincidencias y diferencias. Buenos Aires. EDUCA. 